\title{
Interaction of Weather and Other Contributing Factors in General Aviation Instrument Approach Accidents
}

\author{
Julius C. Keller, Micah S. Walala, and Richard O. Fanjoy \\ Purdue University
}

\begin{abstract}
General aviation accidents continue to be a concern for the Federal Aviation Administration. The purpose of this study was to identify the primary and secondary contributing factors of general aviation instrument approach accidents between the years of 2004-2014; identify the weather conditions of these accidents; and test for an association between the contributing factors and weather conditions during the accidents. Findings suggested that 'Failure to Control' and 'Adverse Weather' were identified as the leading causes of accidents during instrument flight rules operations while 'Failure to Control' and 'Flight Below Published Minimums' were the leading causes of accidents during visual flight rules. A Chi-square test of the data indicated a significant association between weather conditions and reported contributing factors with a moderate level of strength.
\end{abstract}

\section{Introduction}

On September 15, 2012, a U.S. registered Cirrus SR 22 airplane operating in instrument meteorological conditions (IMC) was cleared for an instrument landing system (ILS) approach. A few minutes after acknowledging a frequency change, radar tracking showed the airplane off course by 0.25 miles. The pilot then aborted the approach and requested vectors to attempt a second approach during which radar tracking showed the aircraft drifting back and forth across the localizer centerline by 0.25 miles. The airplane eventually began a flight path parallel to the localizer, 0.12 miles off centerline. The airplane then entered into a left turn which continued until the final data radar point. Additional data indicated the airplane descended at an average of 6,000 feet per minute before it impacted a wooded area six miles northwest of the destination airport killing the pilot and all four passengers. National Transportation Safety Board (NTSB) investigators suggested spatial disorientation experienced during night IMC led the pilot to lose control of the airplane (ASI, n.d.a).

According to the accident report, the pilot had an estimated 1,000 total flight hours including 75 hours of actual instrument time and approximately 650 hours in the make and model of the accident aircraft. Weather conditions recorded by the local Automated Surface Observing System (ASOS) indicated 8 miles of visibility and overcast clouds at 700 feet above ground level (AGL). Although the pilot filed an IFR flight plan, there was no record of a weather briefing associated with the accident aircraft tail number. During 
the period 2004-2014, one hundred and thirty- four general aviation (GA) instrument approach accidents occurred of which approximately $70 \%$ were fatal. (ASI, n.d.a.).

\section{Purpose of Current Study}

General aviation includes all flight operations except air carrier scheduled service (Part 121), non-scheduled air transport flights (Part 135) and military (FAA, 2008). This sector of aviation represents one of the FAA's last unresolved safety areas. Consequently, the FAA has created a five-year plan to improve safety in GA through four main approaches: risk management, outreach and engagement, safety promotion, and training. Risk management entails effective identification of risks and application of mitigating solutions. One of the FAA's methods to reduce accident rates is by collaborating with industry to study accident data and use it to identify risky patterns (FAA, 2011). The approach and landing phases of flight account for the highest number of GA accidents (FAA, 2010a).

The purpose of this exploratory study was to identify contributing factors of GA accidents during the instrument approach phase; classify the weather conditions related to these accidents; and determine whether there was a significant association between contributing factors to accidents and weather conditions. Identifying such relationships can assist the aviation research community to understand how weather can influence the type of errors that result in accidents. This can lead to further research that investigates mitigation strategies to improve GA safety.

\section{Literature Review}

Causes of GA instrument approach accidents include: ineffective or non-existent crew resource management (CRM), adverse weather and physiological factors (FAA, 2009; FAA, 2012; Gibb, Ercoline \& Scharff, 2011; Price \& Groff, 2006). Methods for categorizing causes of GA accidents have included Human Factors Accident Classification System (HFACS) (Wiegmann et al., 2005) and examining probable causes retrieved from accident reports (Fanjoy \& Keller, 2013).

According to the FAA (2009a), a GA flight is more likely to operate with a single pilot rather than a multi pilot crew. CRM was designed to reduce human error by increasing performance and coordination (FAA, 2004). The absence of an additional pilot may partly explain why the GA accident rate has not shown significant improvement over the last decade. In contrast, the Air Carrier accident rate has decreased by $80 \%$ (NTSB, 2012). Results of an 8-year study conducted by Price \& Groff (2006) indicated a multi-engine turbo-prop aircraft with a single pilot was 1.6 times more likely to be involved in an accident when encountering visually degraded conditions when compared to a multi-crew operation in the same type of aircraft.

An FAA study (2012) carried out 26 interviews of GA pilots that requested for help, initiated an emergency or made an alteration while encountering declining or extreme 
weather conditions. Weather conditions at the time of the incident were also examined and analyzed. Results from that study indicated a shortfall in education and training when pilots were tasked with interpreting weather information. The study recommended all pilots undergo additional weather training by authorized instructors.

A method to investigate causes of GA accidents is classification of errors. Wiegmann et al. (2005) used HFACS to analyze GA accidents. The study suggested that skilled based errors contributed the most to accidents followed by decision and perception errors. Poor procedures and instructions were the major latent causes of these accidents. The study recommended increased use of aircraft automation, improved checklists, and workload management training as measures to reduce future accidents. Thus HFACS has enabled adoption of more relevant intervention measures to reduce errors and safety hazards.

An FAA study (2010b) categorized GA weather related accidents as resulting from skill based, decision and perceptual errors. The study noted that skill-based errors were the hardest to understand because in fatal cases, it was often difficult to capture the exact causes. In addition, pilots who survived might have a propensity to alter the facts associated with the accident if they felt their statement could cause self-incrimination. It was also noted, instrument rated pilots were often susceptible to becoming overconfident in their abilities and likely to fly into conditions beyond their capabilities.

Spatial disorientation plays a significant role in GA accidents but has not been adequately addressed. Thirty percent of GA accidents are caused by spatial disorientation and those have nearly a $100 \%$ fatality rate. Further research is needed to develop a more effective reporting process, data analysis, and appropriate mitigating strategies (Gibb, Ercoline \& Scharff, 2011).

An exploratory study conducted by Fanjoy and Keller (2013), used the ASI database to investigate the relationship between primary causes of instrument approach accidents and instrument proficiency checks (IPC). Results suggested more than half of the instrument approach accidents examined occurred within three and half months of the last IPC. A leading cause of these accidents was failure to control the aircraft. Further investigation into IPC training procedures and requirements was suggested.

\section{Methodology}

Researchers for the current study used the Air Safety Institute accident database to acquire data from GA instrument approach accident reports collected over the last ten years. Researchers then performed a filtered search to obtain all fixed wing accidents that occurred while on an instrument approach, resulting in 134 data sets. From these accident reports researchers obtained information which included: accident report number, weather conditions, phase of flight, type of approach, and primary and secondary causes. Next, researchers sorted the data by weather conditions reported at the time of the accident. Some airports did not have weather observation facilities on site. In these cases, secondary 
weather information was used. The secondary weather information was either recorded from a nearby weather observation station or a weather report collected by the accident investigators. The reports obtained from the ASI database are identical to the official NTSB reports.

\section{Categorization of Weather Minimums}

The FAA (2009b) defines and categorizes VFR and IFR weather minimums as follows; low instrument flight rules (LIFR), instrument flight rules (IFR), marginal visual flight rules (MVFR) and visual flight rules (VFR). Researchers used these definitions to categorize weather observations for each data set. These weather categorizations can be viewed in Table 1.

Table 1

Weather Categories

\begin{tabular}{cccc}
\hline Category & Ceiling (AGL) & & Visibility (SM) \\
\hline VFR & Greater than 3,000 feet AGL & and & Greater than 5 miles \\
MVFR & 1,000 to 3,000 feet AGL & and/or & 3 to 5 miles \\
IFR & 500 to 999 feet AGL & and/or & 1 mile to less than 3 miles \\
LIFR & Below 500 feet AGL & and/or & Less than 1 mile \\
\hline
\end{tabular}

Note: VFR and IFR weather categories. Adapted from "General aviation pilot's guide to preflight weather planning, weather self-briefings, and weather decision making" by Federal Aviation Administration, 2009, p. 29.

\section{Categorization of Contributing Factors}

Researchers categorized primary and secondary causes of accidents by using the language found in the accident causes section of the report. Twenty-one categories from the data analysis emerged as the data was analyzed. However, researchers decided to reduce the categories to twelve by combining specific categories. This was done because some categories were similar and/or had a small frequency of occurrence. 'Failure to Follow Published Approach Procedures' includes failure to execute missed approach, 'Failure to control" includes failure to establish approach and 'Situational Awareness' includes controlled flight into terrain. 'Aeromedical Factors' includes fatigue, medical and drugs. 'Lack of Oversight' includes inadequate oversight of air traffic control (ATC), inadequate oversight of FAA, inadequate standard operating procedures (SOP's), inadequate organizational oversight and failure of captain duties. 'Other' includes failed equipment, misuse of automation, undetermined reasons and violations. Table 2 shows the 
final listing of categories and abbreviations. Reference these abbreviations for figures two through six.

Table 2

Categorization of contributing factors

\begin{tabular}{ll}
\hline Aeronautical Decision Making (ADM) & Improper Airspeed (A/S) \\
Adverse Weather (AW) & Lack of Oversight (LOO) \\
Aeromedical Factors (AF) & Other (Other) \\
Failure to Control (FTC) & Situational Awareness (SA) \\
Failure to Follow Published Approach & Spatial Disorientation (SD) \\
Procedures (FFPAP) & Weather Below Published Minimums \\
Flight Below Published Minimums (FBPM) & (WBPM) \\
\hline
\end{tabular}

\section{Findings}

A search of the ASI database produced 134 GA accident reports that happened between 2004 and 2014. Eight data sets were removed. Five of the eight omitted accidents involved airplanes registered outside of the United States. Consequently, these five accidents did not have comprehensive accident reports as the investigations were outside the NTSB's jurisdiction. The remaining three omitted accidents had insufficient information to be considered usable. Therefore, the data set of interest for this study is $(\mathrm{N}=126)$. Of the 126 accidents of interest, their frequencies and categories of weather conditions are graphically presented in Figure 1.

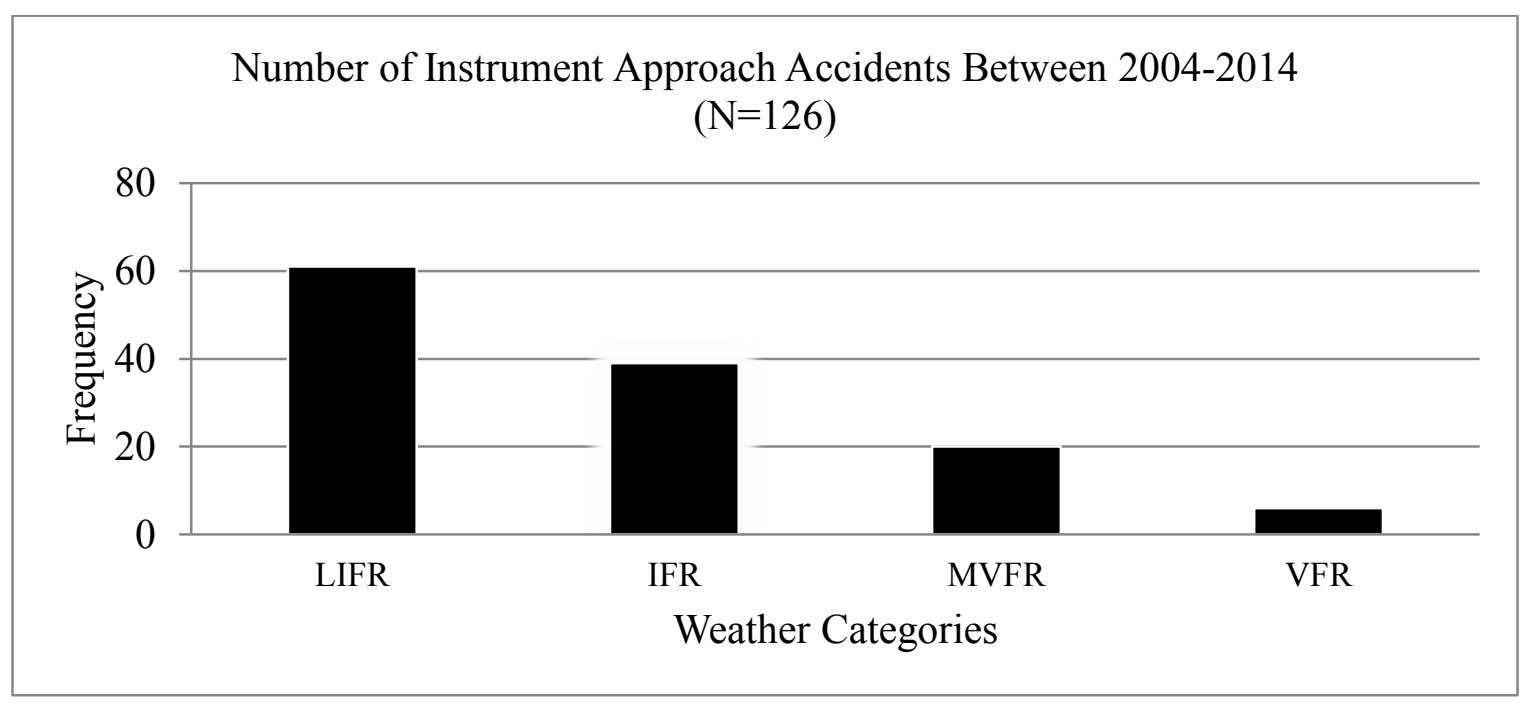

Figure 1. Frequency distribution of instrument approach accidents between 2004-2014. 
The next step in the analysis was to extract primary and secondary contributing factors. Researchers combined primary and secondary causes to provide a perspective on overall contributing factors to accidents, as accidents are likely caused by the totality of the situation. The probable causes of accidents were cross-tabulated against weather conditions. When considering all probable causes and all four weather categories, the order of frequency is depicted in figure 2 .

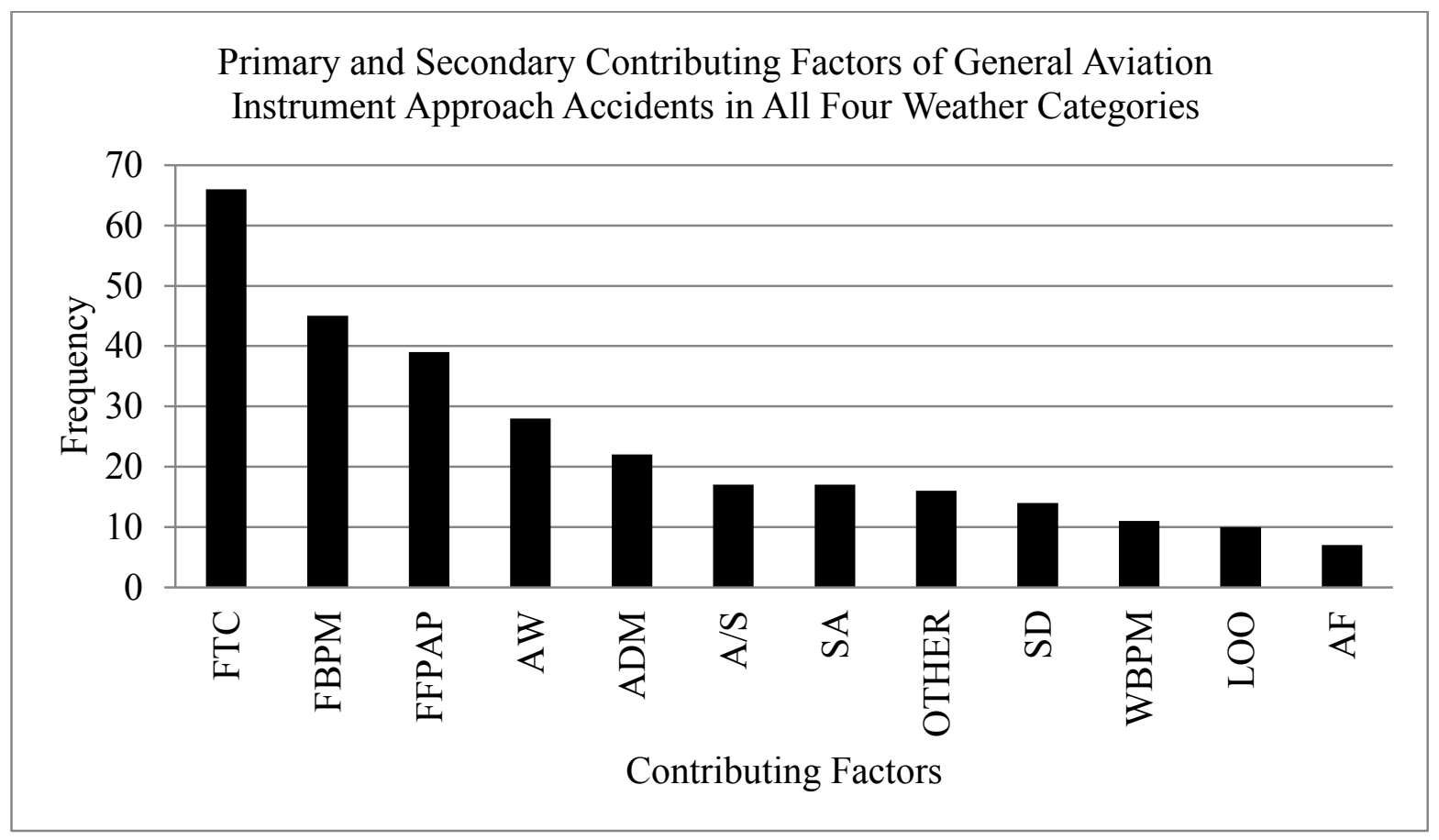

Figure 2. Primary and secondary causes of instrument approach accidents in all four weather categories.

Note: $\mathrm{FTC}=$ 'Failure to Control'; FBPM = 'Flight Below Published Minimums'; FFPAP = 'Failure to Follow Published Approach Procedures'; AW = 'Adverse Weather'; ADM = 'Aeronautical Decision Making'; A/S = 'Improper Airspeed'; SA = 'Situational Awareness'; OTHER = 'Other'; SD = 'Spatial Disorientation'; WBPM = 'Weather Below Published Minimums'; LOO = 'Lack of Oversight'; AF = 'Aeromedical Factors'.

Next, researchers separated the weather categories and identified the causes of accidents in each of the four weather categories. The 61 accidents under LIFR operations had 146 causes listed by the accident investigators while IFR operations had a total of 85 causes. MVFR and VFR operations had 46 and 13 accident causes respectively according to the NTSB investigators. This information is graphically summarized in figures three to six. 


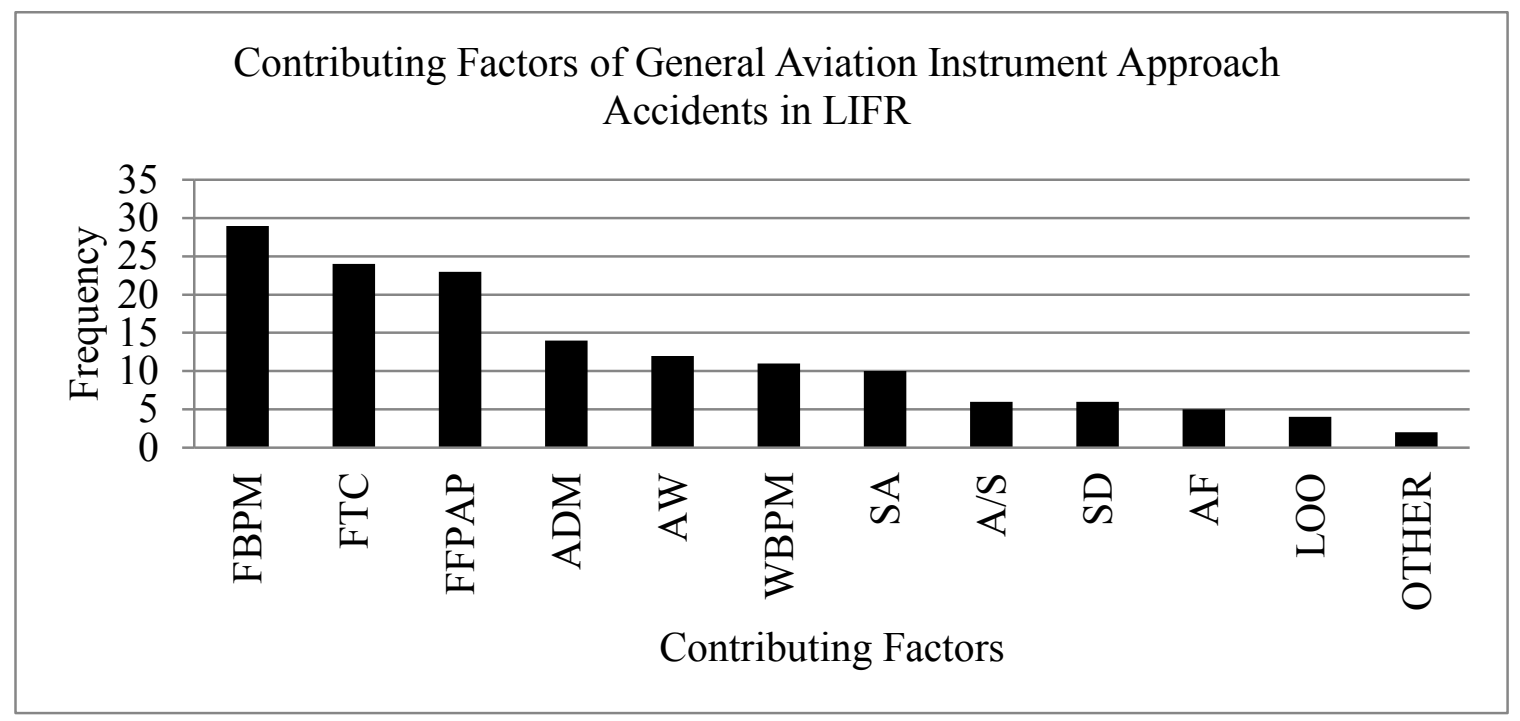

Figure 3. Causes of instrument approach accidents in LIFR.

Note: FBPM = 'Flight Below Published Minimums'; FTC = 'Failure to Control'; FFPAP = 'Failure to Follow Published Approach Procedures'; ADM = 'Aeronautical Decision Making'; AW = 'Adverse Weather'; WBPM = 'Weather Below Published Minimums'; SA = 'Situational Awareness'; A/S = 'Improper Airspeed'; SD = 'Spatial Disorientation'; AF = 'Aeromedical Factors'; LOO = 'Lack of Oversight' OTHER = 'Other'.

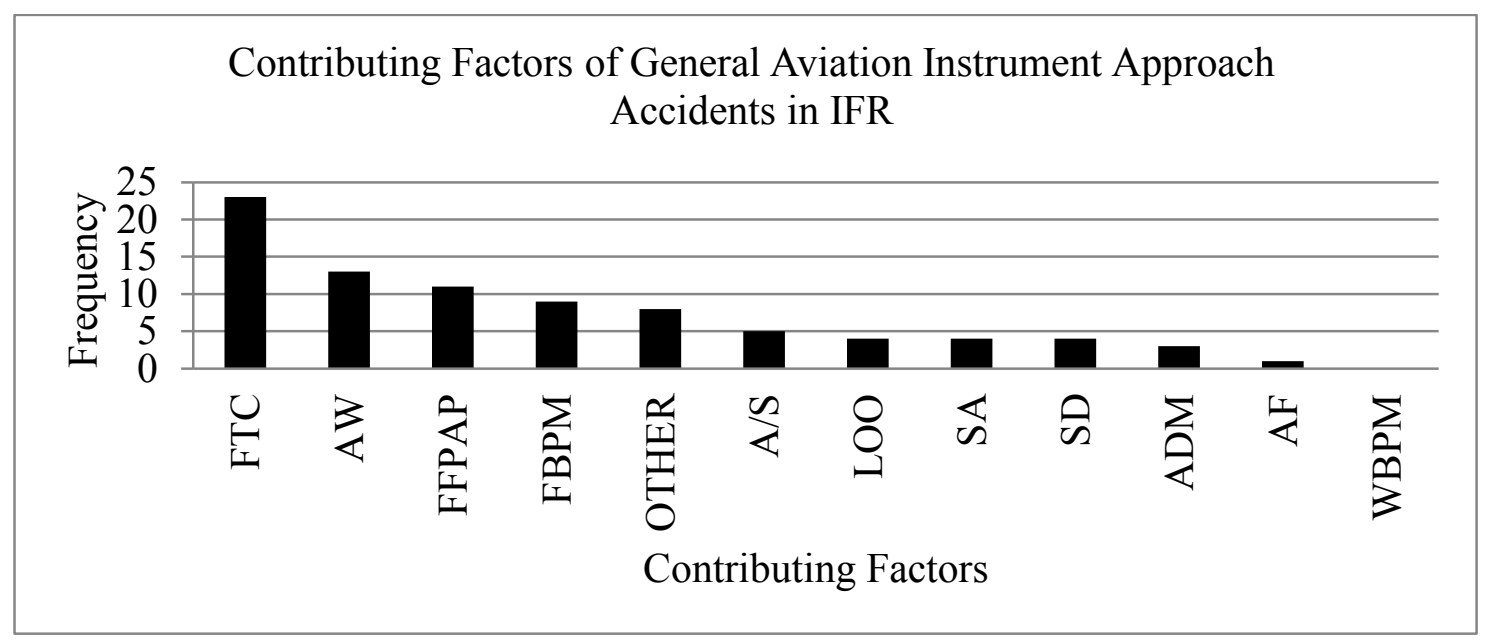

Figure 4. Causes of instrument approach accidents in IFR.

Note: FTC = 'Failure to Control'; AW = 'Adverse Weather'; FFPAP = 'Failure to Follow Published Approach Procedures'; FBPM = 'Flight Below Published Minimums'; OTHER = 'Other'; A/S = 'Improper Airspeed'; LOO = 'Lack of Oversight'; SA = 'Situational Awareness'; SD = 'Spatial Disorientation'; ADM = 'Aeronautical Decision Making'; AF = 'Aeromedical Factors'; WBPM = 'Weather Below Published Minimums'. 


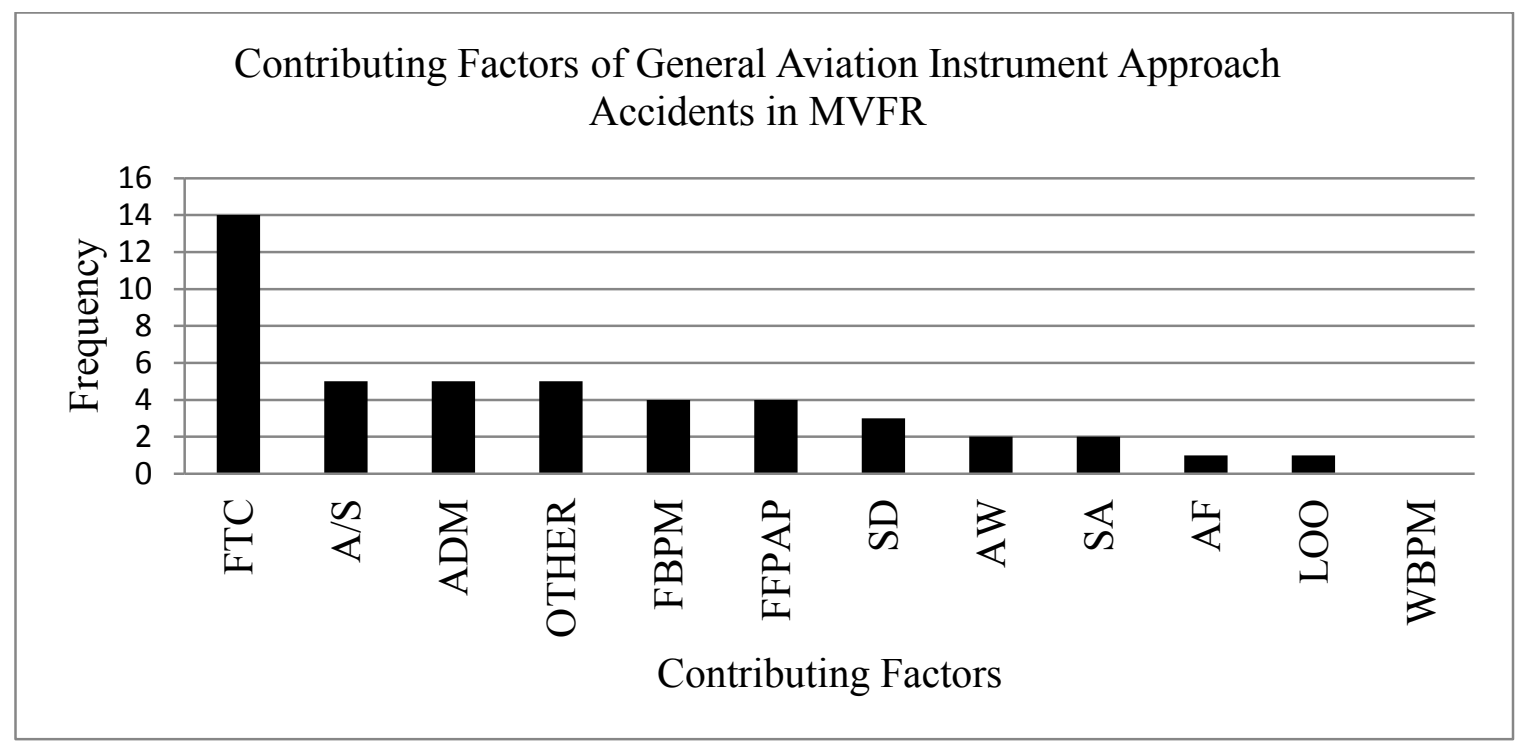

Figure 5. Causes of instrument approach accidents in MVFR.

Note: FTC = 'Failure to Control'; A/S = 'Improper Airspeed'; ADM = 'Aeronautical Decision Making'; OTHER = 'Other'; FBPM = 'Flight Below Published Minimums'; FFPAP = 'Failure to Follow Published Approach Procedures'; SD = 'Spatial Disorientation'; AW = 'Adverse Weather'; SA = 'Situational Awareness'; $\mathrm{AF}=$ 'Aeromedical Factors'; $\mathrm{LOO}=$ 'Lack of Oversight'; WBPM = 'Weather Below Published Minimums'.

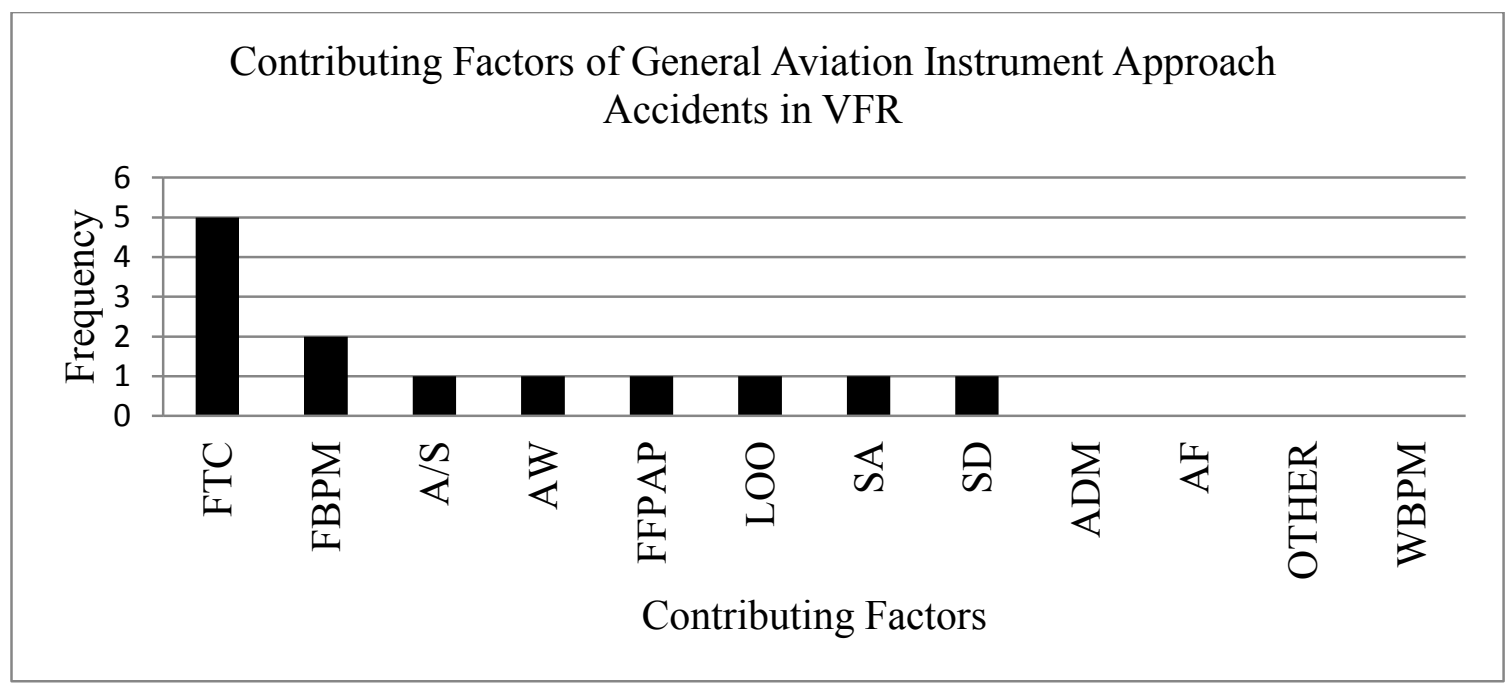

Figure 6. Causes of instrument approach accidents in VFR.

Note: $\mathrm{FTC}=$ 'Failure to Control'; FBPM = 'Flight Below Published Minimums'; A/S = 'Improper Airspeed'; AW = 'Adverse Weather'; FFPAP = 'Failure to Follow Published Approach Procedures'; LOO = 'Lack of Oversight'; SA = 'Situational Awareness'; SD = 'Spatial Disorientation'; ADM = 'Aeronautical Decision Making'; AF = 'Aeromedical Factors'; OTHER = 'Other'; WBPM = 'Weather Below Published Minimums'. 


\section{Chi-Square Analysis}

Of the 126 accidents considered in this dataset, there were a total of 291 causes or contributing factors as cited by the accident investigators. Most of the accidents had more than one cause or contributing factor, such as 'Failure to Control' due to 'Spatial Disorientation'. A Chi- square test was conducted to determine if a significant association between weather categories and causes of accidents exists. The Chi-square probability value was $0.0337(\alpha=.05)$. However, $57 \%$ of the cells had expected counts of less than 5 . Thus, a Fisher's Exact test was conducted using the Monte Carlo method to obtain a more accurate and powerful Chi-square test probability (Pett, 1997). The Fisher's Exact test was $p=<0.0001(\alpha=.05)$ and the Monte Carlo Estimate for the Exact test was $0.0189(\alpha=.05)$. These results provide enough evidence to indicate a statistically significant association between weather categories and causes of accidents. The Cramer's V test was 0.2259 which indicates a moderate level of association. The test statistics can be viewed in Table 3 .

Table 3

Chi-square test probabilities

\begin{tabular}{lccc}
\multicolumn{1}{c}{ Statistic } & DF & Value & Probability \\
\hline Chi-Square & 30 & 45.6297 & 0.0337 \\
Likelihood Ratio Chi-Square & 30 & 51.6842 & 0.0082 \\
Mantel-Haenszel Chi-Square & 1 & 0.0003 & 0.9864 \\
Phi Coefficient & & 0.396 & \\
Contingency Coefficient & & 0.3682 & \\
Cramer's V & & 0.2286 & \\
\hline
\end{tabular}

WARNING: $57 \%$ of the cells have expected counts less than 5 . Chi-Square may not be a valid test.

\begin{tabular}{lr}
\multicolumn{2}{c}{ Monte Carlo Estimate for the Exact Test } \\
\hline Probability $<=p$ & 0.0131 \\
99\% Upper Confidence Limit & 0.0102 \\
99\% Lower Confidence Limit & 0.016 \\
Number of Samples & 10000 \\
Initial Seed & 272055001 \\
\hline \multicolumn{2}{c}{ Sample size $: 291$} \\
\hline
\end{tabular}

Fisher's Exact Test Probability $(\mathrm{P})<0.0001$ 
The leading causes of the accidents for the complete dataset were 'Failure to Control', 'Flight Below Published Minimums' and 'Failure to Follow Published Approach Procedures'. These three causes happened most often during LIFR. In addition, $100 \%$ of accidents with 'Weather Below Published minimums' occurred during LIFR. The top three causes that contributed positively to the overall Chi-square value (45.6297) were 'Weather Below Published Minimums', 'Adverse Weather', and 'Other' with cell Chi-squares $5.4436,2.8421$ and 2.5556 respectively. Causes with the least contribution to the overall Chi-square value were observed in MVFR and VFR weather categories. These results and values can be viewed in Table 4.

Table 4

Chi-square Table of Primary and Secondary Contributing Factors for General Aviation Instrument Approach Accidents

\begin{tabular}{|c|c|c|c|c|c|c|c|c|c|c|c|c|}
\hline \multirow[b]{2}{*}{ Surface WX Conditions } & \multicolumn{12}{|c|}{ Contributing factors } \\
\hline & $\mathrm{A} / \mathrm{S}$ & $\mathrm{ADM}$ & $\mathrm{AF}$ & AW & FBPM & FFPAP & FTC & OTHER & SA & SD & WBPM & Total \\
\hline \multicolumn{13}{|l|}{ IFR } \\
\hline Frequency & 5 & 3 & 1 & 13 & 9 & 11 & 23 & 12 & 4 & 4 & 0 & 85 \\
\hline Expected & 4.9656 & 6.4261 & 2.0447 & 8.1787 & 12.852 & 11.392 & 19.278 & 7.5945 & 4.9656 & 4.0893 & 3.2131 & \\
\hline Cell Chi Square & 0.0002 & 1.8267 & 0.5337 & 2.8421 & 1.1546 & 0.0135 & 0.7185 & 2.5556 & 0.1878 & 0.002 & 3.2131 & \\
\hline Percent & 1.72 & 1.03 & 0.34 & 4.47 & 3.09 & 3.78 & 7.9 & 4.12 & 1.37 & 1.37 & 0 & 29.21 \\
\hline Row Percentage & 5.88 & 3.53 & 1.18 & 15.29 & 10.59 & 12.94 & 27.06 & 14.12 & 4.71 & 4.71 & 0 & \\
\hline Col Percentage & 29.41 & 13.64 & 14.29 & 46.43 & 20.45 & 28.21 & 34.85 & 46.15 & 23.53 & 28.57 & 0 & \\
\hline \multicolumn{13}{|l|}{ LIFR } \\
\hline Frequency & 6 & 14 & 5 & 12 & 29 & 23 & 24 & 6 & 10 & 6 & 11 & 146 \\
\hline Expected & 8.5292 & 11.038 & 3.512 & 14.048 & 22.076 & 19.567 & 33.113 & 13.045 & 8.5292 & 7.0241 & 5.5189 & \\
\hline Cell Chi Square & 0.75 & 0.795 & 0.6304 & 0.2986 & 2.172 & 0.6023 & 2.5082 & 3.8044 & 0.2536 & 0.1493 & 5.4436 & \\
\hline Percent & 2.06 & 4.81 & 1.72 & 4.12 & 9.97 & 7.9 & 8.25 & 2.06 & 3.44 & 2.06 & 3.18 & 50.17 \\
\hline Row Percentage & 4.11 & 9.59 & 3.42 & 8.22 & 19.86 & 15.75 & 16.44 & 4.11 & 6.85 & 4.11 & 7.53 & \\
\hline Col Percentage & 35.29 & 63.64 & 71.43 & 42.86 & 65.91 & 58.97 & 36.36 & 23.08 & 58.52 & 42.86 & 100 & \\
\hline \multicolumn{13}{|l|}{ MVFR } \\
\hline Frequency & 5 & 5 & 1 & 2 & 4 & 4 & 14 & 7 & 2 & 3 & 0 & 47 \\
\hline Expected & 2.7457 & 3.5533 & 1.1306 & 4.5223 & 7.1065 & 6.299 & 10.66 & 4.1993 & 2.7457 & 2.2612 & 1.7766 & \\
\hline Cell Chi Square & 1.8508 & 0.589 & 0.0151 & 1.4068 & 1.358 & 0.8391 & 1.0446 & 1.8679 & 0.2025 & 0.2414 & 1.7766 & \\
\hline Percent & 1.72 & 1.72 & 0.34 & 0.69 & 1.37 & 1.37 & 4.81 & 2.41 & 0.69 & 1.03 & 0 & 16.15 \\
\hline Row Percentage & 10.64 & 10.64 & 2.13 & 4.26 & 8.51 & 8.51 & 29.79 & 14.89 & 4.26 & 6.38 & 0 & \\
\hline Col Percentage & 29.41 & 22.73 & 14.29 & 7.14 & 9.09 & 10.26 & 21.21 & 26.91 & 11.76 & 21.43 & 0 & \\
\hline \multicolumn{13}{|l|}{ VFR } \\
\hline Frequency & 1 & 0 & 0 & 1 & 2 & 1 & 5 & 1 & 1 & 1 & 0 & 13 \\
\hline Expected & 0.7595 & 0.9828 & 0.3127 & 1.2509 & 1.9656 & 1.7423 & 2.9485 & 1.1615 & 0.7595 & 0.6254 & 0.4914 & \\
\hline Cell Chi Square & 0.0762 & 0.9828 & 0.3127 & 0.0503 & 0.0006 & 0.3162 & 1.4275 & 0.0225 & 0.0762 & 0.2243 & 0.4914 & \\
\hline Percent & 0.34 & 0 & 0 & 0.34 & 0.69 & 0.34 & 1.72 & 0.0762 & 0.34 & 0.34 & 0 & 4.47 \\
\hline Row Percentage & 7.69 & 0 & 0 & 7.69 & 15.38 & 7.69 & 38.46 & 7.69 & 7.69 & 7.69 & 7.69 & \\
\hline Col Percentage & 5.88 & 0 & 0 & 3.57 & 4.55 & 2.56 & 7.58 & 3.85 & 5.88 & 7.14 & 0 & \\
\hline \multirow{2}{*}{ Total } & 17 & 22 & 7 & 28 & 44 & 39 & 66 & 26 & 17 & 14 & 11 & 291 \\
\hline & 5.84 & 7.56 & 2.41 & 9.6 & 15.12 & 13.4 & 22.68 & 8.93 & 5.84 & 4.81 & 3.78 & 100 \\
\hline
\end{tabular}

Note. $\mathrm{WX}=$ weather 


\section{Discussion and Conclusions}

Flying an instrument approach in IMC is more complex than flying an instrument approach in VFR weather. For instance, single pilot operations in IMC may require prolonged concentration and it is likely that a single pilot will encounter an increase in workload compared to VMC operations (AOPA, 2006). Previous research has indicated there are various factors that cause instrument approach accidents (Fanjoy and Keller, 2013; Fanjoy and Young, 2005; Weigmann et al, 2005; Weigmann and Shappell, 2000). Factors such as spatial disorientation and overconfidence in personal abilities are typical causes in instrument approach accidents.

Findings from this study suggest that accidents and errors decrease as weather conditions improve. It was anticipated that the LIFR weather category would account for greatest association with accident contributing factors because it contained the most accidents. This was the case with all but two contributing factors; 'Adverse Weather' and 'Other' were the highest during IFR conditions. It is possible that pilots may cancel their IFR clearance and continue with a visual approach or may not file IFR at all if weather conditions permit. When flying in LIFR conditions there is a lower margin of error because outside visual cues are expected later in the approach. In that case, it takes considerable experience to manage the workload, recognize cues and transition from the approach phase to a landing or missed approach segment. In LIFR conditions, some pilots may not adhere to personal limitations and may continue an approach in conditions beyond their experience or ability. Previous research (Kim, 2011) has shown pilots tend to be overconfident which may affect their aeronautical decision making process. This may lead to "ducking under" minimums, choosing not to divert, impulsiveness, resignation, anti-authority, "machoness", and being distracted.

Flight below published minimums was the leading cause for accidents during LIFR while failure to control was the leading cause in IFR, MVFR and VFR weather categories. When analyzing the data with all accident causes and all four weather categories, failure to control was the leading contributing factor followed by flight below published minimums. Pilots may be reluctant to divert because of time, money and pressure. Flight in LIFR conditions does not provide enough room to "duck under", look for the runway, and maintain clearance from obstacles.

Results from the Chi square table suggested a moderately strong association between the weather categories and other contributing factors. As weather deteriorates, precise aircraft control becomes more difficult. In this case, an increased workload may decrease a pilot's performance thus increasing errors. There may also be psychological factors involved. For example, it can be difficult to recognize and or admit when fatigue begins to degrade performance.

This exploratory project sought to identify patterns of contributing factors to instrument approach accidents and how those factors are associated with different weather categories. 
The focus of this research is in support of FAA's initiative to identify risks through data analysis as a proactive approach to improving GA safety. Since this study used a small non-randomized sample, generalizations regarding the current GA pilot population would be inappropriate. However, knowledge of the association between causes of accidents and weather conditions provides a good precedent for further research. Such research could include evaluation of additional variables such as approach types, number of pilots and environmental factors for cross tabulation. Scenario based simulator experiments with pilots could also be effective for identifying missing cognitive cues that are essential for safe operations. Finally, in concert with research initiatives, continued design and evaluation of cost effective technology should be explored to address this particular issue in GA flight. 


\section{References}

Aircraft Owners and Pilot Association. (2006). Single pilot IFR. Retrieved from http://www.aopa.org//media/Files/AOPA/Home/Pilot\%20Resources/ASI/Safety\%20Advisors/sa05.pdf

Air Safety Institute. (n.d.a). Accident Analysis. Retrieved from: http://www.aopa.org/asf/ntsb/narrative.cfm?ackey=1\&evid=20120915X35028 Accident Safety Institute.

Air Safety Institute. (n.d.b). 2011-2012 GA accident scorecard. Retrieved from http://www.aopa.org/media/Files/AOPA/Home/Pilot\%20Resources/Safety\%20\& \%20Proficiency/Accident\%20Analysis/Nall\%20Report/ASI\%20GA\%20Scorecar d\%202011_2012.pdf

Fanjoy, R. O., \& Keller, J. C. (2013). Flight Skill Proficiency Issues in Instrument Approach Accidents. Journal of Aviation Technology \& Engineering,3(1), 17-23.

Fanjoy, R. O., \& Young, J. P. (2005). Flight deck automation: Line pilot insight for improved initial pilot training. International Journal of Applied Aviation Studies, $5(1), 13-24$.

Federal Aviation Administration (2008). Plane sense general aviation information. Retrieved from http://www.faa.gov/regulations_policies/handbooks_manuals/aviation/media/faah-8083-19a.pdf

Federal Aviation Administration. (2009a). Risk management handbook. Retrieved from https://www.faa.gov/regulations_policies/handbooks_manuals/aviation/risk_mana gement_handbook/media/risk_management_handbook.pdf 
Federal Aviation Administration. (2009b). General aviation pilot's guide to preflight weather planning, weather self-briefings, and weather decision making Retrieved from http://www.faa.gov/pilots/safety/media/ga_weather_decision_making.pdf

Federal Aviation Administration. (2010a). 2010 Faasteam Safety Stand down. Retrieved from https://www.faasafety.gov/files/notices/2010/May/FAA_Safety_Stand_Down_Broc hure.pdf

Federal Aviation Administration. (2004). Crew resource management training. (FAA AC NO: 120-51E). Retrieved from http://www.faa.gov/documentLibrary/media/Advisory_Circular/AC120-51e.pdf

Federal Aviation Administration. (2010b). Causes of general aviation weather-related, non-fatal: analysis using NASA aviation safety reporting system data. (DOT/FAA/AM-10/13). Washington, DC: Office of Aerospace Medicine.

Federal Aviation Administration. (2011). Transforming general aviation safety five-year strategy. Retrieved from https://www.faa.gov/about/office_org/headquarters_offices/avs/offices/afs/afs800/ media/FAA_Transform_GA_Safety_Strategy.pdf

Federal Aviation Administration (2012). General aviation weather encounter case studies. (DOT/FAA/AM-12/11). Washington, DC: Office of Aerospace Medicine.

Federal Aviation Administration (2014). Fact sheet-general aviation safety. Retrieved from https://www.faa.gov/news/fact_sheets/news_story.cfm?newsId=13672

Gibb, R., Ercoline, B., \& Scharff, L. (2011). Spatial disorientation: decades of pilot Fatalities. Aviation, space, and environmental medicine, 82(7), 717-724.

Kay, A., Liston, P. M., \& Cromie, S. (2014). Measuring Crew Resource Management: Challenges and Recommendations. In Harris. D. (Eds.) Engineering Psychology and Cognitive Ergonomics, 480-490. New York: Springer

Kim, C. (2011). The effects of weather recognition training on general aviation pilot situation assessment and tactical decision making when confronted with adverse weather conditions (Doctoral dissertation, Clemson University).

National Transportation Safety Board. (2012). General aviation accidents: The NTSB most wanted list. Retrieved from http://www.ntsb.gov/doclib/speeches/weener/weener_011912.pdf 
Pett, M. A. (1997). Nonparametric statistics in health care research: Statistics for small samples and unusual distributions. Thousand Oaks, CA: Sage.

Price, J. M. \& Groff, L. S. (2006). Risk factors for fatal general aviation accidents in degraded visual conditions. Retrieved from http://www.faa.gov/about/initiatives/maintenance_hf/library/documents/media/hu man_factors_maintenance/risk_factors_for_fatal_general_aviation_accidents_in_ degraded_visual_conditions.pdf

Wiegmann, D. A., \& Shappell, S. A. (2000). Human error perspectives in aviation. The International Journal of Aviation Psychology, 11(4), 341-357.

Wiegmann, D. A., Shappell, S., Boquet, A., Detwiler, C., Holcomb, K., \& Faaborg, T. (2005). Human error and general aviation accidents: A comprehensive, fine grained analysis using HFACS. Retrieved from http://www.humanfactors.illinois.edu/Reports\&PapersPDFs/TechReport/0508.pdf 